Pesq. Vet. Bras. 36(3):187-196, março 2016 DOI: $10.1590 / \mathrm{S} 0100-736 \mathrm{X} 2016000300007$

\title{
Sensibilidade e especificidade do exame eletrocardiográfico na detecção de sobrecargas atriais e/ou ventriculares em gatos da raça Persa com cardiomiopatia hipertrófica ${ }^{1}$
}

\author{
Arine Pellegrino ${ }^{2 *}$, Alexandre G.T. Daniel ${ }^{3}$, Rebecca Pessoa ${ }^{2}$, Juliana M. Guerra ${ }^{4}$, \\ Gabriel Garone de Lucca², Marcelo D. Goissis ${ }^{5}$, Mariana F. Freitas ${ }^{2}$, Bruno Cogliati ${ }^{4}$ \\ e Maria Helena M.A. Larsson ${ }^{2}$
}

\begin{abstract}
Pellegrino A., Daniel A.G.T., Pessoa R., Guerra J.M., Lucca G.G., Goissis M.D., Freitas M.F., Cogliati B. \& Larsson M.H.M.A. 2016. [Sensitivity and specificity of electrocardiographic examination in detecting ventricular or atrial overloads in Persian cats with hypertrophic cardiomyopathy.] Sensibilidade e especificidade do exame eletrocardiográfico na detecção de sobrecargas atriais e/ou ventriculares em gatos da raça Persa com cardiomiopatia hipertrófica. Pesquisa Veterinária Brasileira 36(3):187-196. Departamento de Clínica Médica, Faculdade de Medicina Veterinária e Zootecnia, Universidade de São Paulo, Av. Prof. Dr. Orlando Marques de Paiva 87, São Paulo, SP 05508-270, Brazil. E-mail: arinepel@yahoo.com.br

Hypertrophic cardiomyopathy (HCM) is the most common feline heart disease and is characterized by increased cardiac mass with a hypertrophied and not dilated left ventricle. The echocardiography is the best noninvasive diagnostic tool for the differentiation of cardiomyopathies and is considered the gold standard for detection of ventricular hypertrophy present in HCM. Electrocardiographic changes are also common in animals with HCM and the electrocardiogram (ECG) is quick, easy and highly available screening test for the detection of ventricular hypertrophy in humans. In cats, few studies have been conducted regarding the sensitivity and specificity of ECG in detecting ventricular hypertrophy. With the intention of evaluating the use of ECG as a screening tool for diagnosis of HCM in cats, Persian cats $(n=82)$ were evaluated by echocardiographic and electrocardiographic examinations. Animals with blocks and/or conduction disturbances were excluded from statistical analysis $(\mathrm{n}=22)$. Subsequently the animals included were classified as normal $(n=38)$, suspicious $(n=6)$ and affected by HCM $(n=16)$. Statistical differences were observed in the P-wave amplitude in DII and R-wave amplitude in DII, CV6LL and CV6LU, with higher values in animals with HCM. Velocities and pressure gradient of aortic flow, left atrial diameter (LA) and LA/Ao ratio were higher in cats with HCM. Among the animals with ECG changes suggestive of left atrial enlargement ( $n=7)$, only two actually had LA enlargement on echocardiography, and among animals with left atrial enlargement on echocardiogram ( $n=7)$, only two had ECG changes suggestive of overload AE $(40,4 \%$ of sensibility and $90,9 \%$ of specificity). Among the animals with ECG changes suggestive of left ventricular hypertrophy $(n=6)$, five actually had ventricular hypertrophy on echocardiography, and among animals with HCM by echocardiography $(n=16)$, only five showed electrocardiographic abnormalities suggestive of LV hypertrophy $(31,25 \%$ of sensibility and $97,72 \%$ of
\end{abstract}

\footnotetext{
${ }^{1}$ Recebido em 6 de abril de 2015.

Aceito para publicação em 2 de fevereiro de 2016.

${ }^{2}$ Departamento de Clínica Médica, Faculdade de Medicina Veterinária e Zootecnia (FMVZ), Universidade de São Paulo (USP), Av. Prof. Dr. Orlando Marques de Paiva 87, Cidade Universitária, São Paulo, SP 05508-270, Brasil.*Autor para correspondência: arinepel@yahoo.com.br

3 Faculdade de Medicina Veterinária, Universidade Metodista de São
}

Paulo, Av. Dom Jaime de Barros Câmara 100, Planalto, São Bernardo do Campo, SP 09895-400, Brasil.

${ }^{4}$ Departamento de Patologia, FMVZ-USP, Av. Prof. Dr. Orlando Marques de Paiva 87, Cidade Universitária, São Paulo, SP 05508-270, Brasil.

${ }^{5}$ Departamento de Reprodução, FMVZ, Universidade de São Paulo. Av. Prof. Dr. Orlando Marques de Paiva 87, Cidade Universitária, São Paulo, SP 05508-270, Brasil. 
specificity). We observed a positive correlation between diastolic thickness of the interventricular septum and/or left ventricular free wall and R-wave amplitude in DII and CV6LU. The electrocardiogram is quick and easy to perform, has good specificity in detecting ventricular hypertrophy in cats, however, has low sensitivity, with large numbers of false negative animals. Thus, the ECG assists in the diagnosis, but does not replace echocardiography in confirming ventricular hypertrophy.

INDEX TERMS: Electrocardiography, hypertrophic cardiomyopathy, cats, Persian, echocardiography.

RESUMO.- A cardiomiopatia hipertrófica (CMH) é a principal cardiopatia dos felinos e é caracterizada por hipertrofia miocárdica concêntrica, sem dilatação ventricular. 0 ecocardiograma é o melhor meio diagnóstico não invasivo para a diferenciação das cardiomiopatias e é considerado padrão ouro para a deteç̧ão de hipertrofia ventricular presente na CMH. Alterações eletrocardiográficas também são comuns em animais com CMH e o eletrocardiograma (ECG) é um teste de triagem para detecção de hipertrofia ventricular em humanos, sendo um exame rápido e facilmente disponível. Em gatos, poucos estudos foram realizados quanto à sensibilidade e especificidade do ECG na detecção de hipertrofia ventricular. Com a intenção de avaliar o uso do ECG como ferramenta de triagem para diagnóstico de $\mathrm{CMH}$ em felinos, gatos da raça Persa $(n=82)$ foram avaliados por meio de exames ecocardiográfico e eletrocardiográfico. Animais com bloqueios e/ou distúrbios de condução foram excluídos da análise estatística $(n=22)$. Posteriormente, os animais incluídos foram classificados em: normais $(n=38)$, suspeitos $(n=6)$ e acometidos pela CMH $(n=16)$. Observaram-se diferenças estatísticas na amplitude da onda P em DII e na amplitude de onda R em DII, CV6LL e CV6LU, com valores maiores nos animais com $\mathrm{CMH}$; e nos valores ecocardiográficos de velocidade e gradiente de pressão do fluxo aórtico, diâmetro do átrio esquerdo (AE) e relação $\mathrm{AE} / \mathrm{Ao}$, com valores maiores nos gatos com CMH. Dentre os animais com alterações eletrocardiográficas sugestivas de sobrecarga atrial esquerda $(n=7)$, apenas dois realmente apresentavam aumento do AE no ecocardiograma; e dentre os animais com aumento atrial esquerdo ao ecocardiograma ( $n=7)$, apenas dois apresentavam alterações eletrocardiográficas sugestivas de sobrecarga do AE (sensibilidade de 40,40\% e especificidade de 90,90\%). Dentre os gatos com alterações eletrocardiográficas sugestivas de sobrecarga ventricular esquerda $(n=6)$, cinco realmente apresentavam hipertrofia ventricular ao ecocardiograma; e dentre os animais com $\mathrm{CMH}$ ao ecocardiograma $(\mathrm{n}=16)$, apenas cinco apresentaram alterações eletrocardiográficas sugestivas de sobrecarga do VE (sensibilidade de $31,25 \%$ e especificidade de $97,72 \%$ ). Observou-se correlação positiva entre espessura diastólica do septo interventricular e/ou da parede livre do ventrículo esquerdo e a amplitude da onda $\mathrm{R}$ em derivações DII e CV6LU. O eletrocardiograma é um exame rápido e de fácil execução, apresenta boa especificidade na detecção de hipertrofia ventricular em felinos, porém, possui baixa sensibilidade, com grande número de falsos negativos. Desta forma, o ECG auxilia no diagnóstico, mas não substitui o ecocardiograma na confirmação da hipertrofia ventricular.

TERMOS DE INDEXAÇÃO: Eletrocardiografia, cardiomiopatia hipertrófica, gatos, Persa, ecocardiografia.

\section{INTRODUÇÃO}

A CMH é caracterizada por hipertrofia ventricular esquerda, sem dilatação (Fox 1999, Chetboul et al. 2006, McDonald et al. 2007). Trata-se da principal cardiopatia dos felinos, associando-se ao desenvolvimento de insuficiência cardíaca, tromboembolismo e morte súbita (Sampedrano et al. 2009). É uma afecção geneticamente e fenotipicamente heterogênea e, em algumas raças de felinos, pode estar associada à mutação autossômica dominante em genes que codificam proteínas do sarcômero (Kittleson et al. 1999).

0 espessamento miocárdico determina o aumento na rigidez ventricular e, consequentemente, o desenvolvimento de alterações no relaxamento (McDonald 2005). Pressões diastólicas aumentadas são necessárias devido à rigidez e à menor distensibilidade ventricular (Chetboul et al. 2006, Gundler Tidholm \& Haggstrõm 2008). 0 ventrículo esquerdo (VE), mais rígido, requer pressões de enchimento maiores e, consequentemente, as pressões diastólicas atriais e ventriculares aumentam (Ware 2007, Boon 2011). Vários fatores podem contribuir para o desenvolvimento de isquemia miocárdica, como: densidade capilar inadequada para o grau de hipertrofia; estreitamento das artérias coronarianas intramurais; diminuição da pressão de perfusão da artéria coronariana; e aumento de pressão de enchimento do VE (Kittleson 1999, McDonald 2005). A isquemia prejudica o relaxamento ventricular ativo, causa aumento de pressão de enchimento ventricular e predispõe a fibroses e arritmias (Fox et al. 1999).

0 ecocardiograma é o exame mais utilizado para avaliação da anatomia e função cardíacas (Thomas et al. 1993), constituindo-se no melhor meio diagnóstico não invasivo para a diferenciação das cardiomiopatias e é considerado padrão ouro para a detecção de hipertrofia ventricular presente na CMH (Chetboul et al. 2006). A identificação dos quatro componentes básicos (hipertrofia, disfunção diastólica, regurgitação mitral e obstrução de via de saída) e a correta interpretação das informações permite abordagem terapêutica adequada (Ferasin 2009, Boon 2011).

Alterações eletrocardiográficas também são comuns em animais com CMH e incluem alterações indicativas de aumentos atrial e ventricular, taquiarritmias ventriculares ou supraventriculares, desvio de eixo elétrico e alterações de condução (Tilley 1992, Ware 2007).

0 eletrocardiograma (ECG) é um teste de triagem para detecção de hipertrofia ventricular em humanos, é rápido e facilmente disponível (Ryan et al. 1995, Caselli et al. 2009, Killian et al. 2010, Hsu et al. 2012). É utilizado como primeira ferramenta para diagnóstico de condições que predispõem à morte súbita (Pelto Owens \& Drezner 2013). Alterações eletrocardiográficas na CMH são bastante variá- 
veis e muitas vezes inespecíficas, mas comumente observadas em humanos carreadores de mutação antes mesmo da hipertrofia ventricular (Ryan et al. 1995, Konno et al. 2005, Lakdawala et al. 2011, Mattos et al. 2013). O ECG, em humanos, pode ser um sensível indicador da doença e uma ferramenta útil para a pesquisa da afecção em indivíduos de famílias acometidas (Namdar et al. 2012).

De acordo com Ryan et al. (1995), apesar do ecocardiograma ser o exame fundamental para o diagnóstico da $\mathrm{CMH}$, o ECG apresenta boa sensibilidade como ferramenta de triagem. A sensibilidade do ECG em identificar a $\mathrm{CMH}$ pode estar relacionada às alterações de condução elétrica decorrentes do desarranjo dos miócitos e miofibrilas, enquanto que o ecocardiograma permite conclusão diagnóstica apenas na ocorrência de hipertrofia ventricular (Ryan et al. 1995, Song et al. 2013). Porém, segundo Lakdawala et al. (2011), o ECG mostrou boa especificidade mas baixa sensibilidade para diagnóstico da mutação, antes da hipertrofia ventricular.

O diagnóstico eletrocardiográfico de hipertrofia ventricular em humanos é baseado no aumento da voltagem dos complexos QRS em diferentes derivações (critério de voltagens) (Murphy et al. 1985, Konno et al. 2005, Bacharova 2009). No entanto, estudos revelam baixa sensibilidade do eletrocardiograma e baixa correlação entre a amplitude do QRS e o grau de hipertrofia (Bender et al. 2012, Rowin et al. 2012). Porém, a presença de alterações eletrocardiográficas que sugerem hipertrofia ventricular em humanos pode ser considerada um marcador prognóstico e de gravidade, permitindo estratificação de risco (Bacharova 2009).

Em gatos, poucos estudos foram realizados quanto à sensibilidade e à especificidade do ECG na detecção de hipertrofia ventricular. Num estudo em felinos com cardiomiopatia dilatada, $\mathrm{CMH}$ ou hipertireoidismo, o ECG indicou incorretamente aumento ventricular em gatos com hipertireoidismo e não detectou, de forma consistente, a presença de sobrecarga em pacientes com CMH. Além disso, o ECG foi um pobre indicador de sobrecarga atrial nos gatos (Moise et al. 1986). Em outro estudo, ao comparar o ECG com avaliação ecocardiográfica, observou-se que gatos com aumento do átrio esquerdo apresentavam onda $\mathrm{P}$ e intervalo PR com maior duração, com baixa sensibilidade mas alta especificidade (Schober et al. 2007).

O ECG é um exame rápido, de baixo custo e amplamente difundido nas clínicas veterinárias; e seu uso como ferramenta de triagem auxilia na pesquisa da afecção em felinos. O objetivo do presente trabalho é avaliar a sensibilidade e a especificidade do eletrocardiograma para a detecção de sobrecargas ventriculares e/ou atriais em gatos com $\mathrm{CMH}$.

\section{MATERIAL E MÉTODOS}

Após aprovação da Comissão de Bioética (CEUA N- 2725201113), foram incluídos nos grupos experimentais 100 gatos da raça Persa, machos e fêmeas, de cinco a 168 meses $(52,459 \pm 40,54$ meses) e peso corpóreo de 2,0 a 7,95 kg (3,96 $\pm 1,34 \mathrm{~kg})$. Antes da inclusão nos grupos experimentais, os gatos foram avaliados por anamnese, exame físico e exames laboratoriais, como: hemograma, dosagem de ureia e creatinina séricas, determinação da atividade das enzimas hepáticas, dosagem de proteína total e albumina sé- ricas, dosagem de eletrólitos séricos (sódio, potássio, cálcio total e fósforo) e dosagem de hormônio tireoidiano T4 total. Realizou-se, também, a mensuração da pressão arterial de acordo com metodologia já estabelecida por Brown et al. (2007).

Foram excluídos do estudo animais que apresentaram alterações que pudessem causar hipertrofia miocárdica secundária, como gatos com hipertensão arterial sistêmica, nefropatia e/ou hipertireoidismo. Também foram excluídos animais que apresentaram infecções evidentes, elevação sérica de enzimas hepáticas, e/ou alterações nos valores séricos de eletrólitos.

0 exame eletrocardiográfico foi realizado no eletrocardiógrafo ECAFIX ${ }^{\circledR}$ modelo ECG 6 com os gatos posicionados em decúbito lateral direito (Harvey et al. 2005), registrando-se as derivações bipolares I, II e III e as unipolares aumentadas aVR, aVL e aVF, bem como as precordiais CV5RL (rV2), CV6LL (V2), CV6LU (V4) e V10 em velocidade de registro de $25 \mathrm{~mm} / \mathrm{s}$ e calibração de $1 \mathrm{mV}$ igual a $1 \mathrm{~cm}$. Posteriormente, a derivação bipolar II foi registrada em velocidade de $50 \mathrm{~mm} / \mathrm{s}$. Os parâmetros eletrocardiográficos foram avaliados de acordo com Tilley (1992), por dois observadores cegos quanto ao diagnóstico ecocardiográfico. As variáveis analisadas foram: frequência cardíaca; ritmo cardíaco; eixo cardíaco elétrico; largura e amplitude da onda P; intervalo PR; largura do complexo QRS; amplitude de onda R; intervalo QT; polaridade e altura da onda T; avaliação do segmento ST quanto ao nivelamento e à morfologia; amplitude das ondas $\mathrm{R}$ e $\mathrm{S}$ e polaridade das ondas T nas derivações precordiais CV5RL (rV2), CV6LL (V2) e CV6LU (V4); polaridade dos complexos QRS e das ondas T na derivação precordial V10. De acordo com Tilley (1992), considerou-se alteração eletrocardiográfica sugestiva de aumento atrial esquerdo a duração da onda P superior a 0,04 s. Complexo QRS com duração superior a 0,04 s, onda R com amplitude superior a 0,9 $\mathrm{mV}$ em derivação DII e/ou onda R com amplitude superior a 1,0 $\mathrm{mV}$ em derivações precordiais CV6LL e/ou CV6LU foram consideradas alterações eletrocardiográficas indicativas de sobrecarga ventricular esquerda (Tilley 1992).

0 exame ecocardiográfico foi realizado no ecocardiógrafo modelo Vivid I (General Electric Co.- GE), conforme recomendações da Echocardiography Committee of the Specialty of Cardiology - American College of Veterinary Internal Medicine (Thomas et al. 1993) e American Society of Echocardiography (ASE) (Nagueh et al. 2009, Boon 2011). Os animais, livres de sedação e/ou tranquilização, foram mantidos em monitorização eletrocardiográfica simultânea à realização do ecocardiograma.

Foram realizadas, no mínimo, três determinações de cada parâmetro avaliado nas diferentes fases do ciclo cardíaco, considerando-se a média dos valores obtidos. As imagens para a mensuração do ventrículo esquerdo foram adquiridas na janela paraesternal direita, corte transversal, na altura da inserção das cordoalhas tendíneas nos músculos papilares (modo M). A ocorrência de hipertrofia miocárdica foi definida quando a espessura diastólica do septo interventricular (SIVd) e/ou da parede livre do ventrículo esquerdo (PVEd) era igual ou superior a 0,6 cm (Sampedrano et al. 2009). Os gatos com espessuras diastólicas menores que $0,5 \mathrm{~cm}$ foram considerados normais; e aqueles com valores de espessuras diastólicas entre 0,5 e 0,6 foram considerados suspeitos para a CMH. A hipertrofia concêntrica foi considerada simétrica quando a relação SIVd/PVEd estava entre 0,7 e 1,3. Na presença de hipertrofia assimétrica, procedeu-se a mensuração da hipertrofia segmentar pelo modo bidimensional. As mensurações do diâmetro da raiz da aorta (Ao) e do diâmetro do átrio esquerdo (AE) foram realizadas pelo modo bidimensional (Abbott \& Mclean 2006), janela paraesternal direita, corte transversal, em região de base cardíaca. Considerou-se aumento do $\mathrm{AE}$ quando a relação AE/Ao foi superior a 1,5 (Wess et al. 2010). 
Após interpretação ecocardiográfica e avaliação de critérios de exclusão, foram eliminados do estudo 16 gatos cujos exames realizados estavam com dados incompletos ou inadequados para interpretação, um gato com cardiomiopatia associada à presença de banda moderadora e um felino com cardiomiopatia arritmogênica do ventrículo direito. Desta forma, foram aceitos, de acordo com os critérios de inclusão, 82 animais, que foram classificados, quanto à $\mathrm{CMH}$, em gatos normais; suspeitos para $\mathrm{CMH}$; e com $\mathrm{CMH}$.

Na análise estatística, utilizou-se o programa SAS 9.3 (SAS Institute, Cary, $N C, E U A$ ). Os dados foram analisados em relação à normalidade da distribuição no PROC UNIVARIATE. Para a análise de correlações entre as variáveis, utilizou-se o PROC CORR do SAS. Optou-se pela Correlação de Spearman devido ao fato de algumas variáveis não apresentarem distribuição normal. As análises comparativas foram realizadas por ANOVA seguida do teste Tukey para comparação de médias utilizando o PROC GLM. Os grupos de animais foram considerados variáveis independentes; e cada variável observada foi considerada variável dependente. Os dados que não apresentaram distribuição normal foram transformados em escala logarítmica e retransformados para apresentação. As variáveis que não atingiram os critérios de normalidade após a transformação foram analisadas por ANOVA não-paramétrica utilizando PROC NPAR1WAY, considerando as mesmas variáveis independentes descritas acima. Comparações grupo a grupo foram realizadas quando o resultado da ANOVA não-paramétrica foi significativo. Em todas as análises, uma diferença estatística de $5 \%(p<0,05)$ foi considerada significante. As determinações de sensibilidade, especificidade, acurácia, valor preditivo positivo, valor preditivo negativo, razão de probabilidade positiva e razão de probabilidade negativa foram realizadas de acordo com Siegel \& Castellan (1988) e Neter et al. (1996).

\section{RESULTADOS}

Dos 82 gatos da raça Persa avaliados, 35 eram machos $(42,68 \%)$ e 47 fêmeas $(57,32 \%)$. De todos os machos, 24 eram inteiros $(68,57 \%)$ e 11 orquiectomizados $(31,43 \%)$. Dentre as fêmeas, apenas 12 eram castradas $(25,53 \%)$ e a maioria inteira $(74,47 \%)$. 0 peso corpóreo variou de 2,0 a

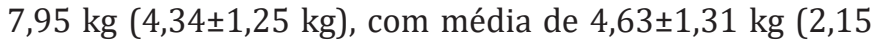
a 7,95 kg) nos machos e 3,86 $\pm 1,05 \mathrm{~kg}(2,0$ a $5,95 \mathrm{~kg})$ nas fêmeas. A média do peso dos machos foi maior que das fêmeas; e dos animais inteiros $(3,46 \pm 1,02 \mathrm{~kg})$ foi inferior que dos gatos castrados $(4,75 \pm 1,23 \mathrm{~kg})$.

A faixa etária variou de 10 a 168 meses $(61,71 \pm 40,56$ meses), com média de 74,22 444,18 meses nos machos e $52,40 \pm 39,56$ nas fêmeas.

Em relação à cardiomiopatia hipertrófica, 54 gatos foram considerados normais $(65,87 \%)$, seis suspeitos $(7,31 \%)$ e 22 acometidos pela CMH (26,82\%). Os valores (média, desvio padrão, mínimo e máximo) de peso corpóreo e idade e a distribuição sexual (porcentagem de machos e fêmeas) nos diferentes grupos estão descritos no Quadro 1. Foram observadas diferenças estatísticas em relação à idade e à distribuição sexual nos diferentes grupos, com idade significativamente maior nos animais com $\mathrm{CMH}$ $(\mathrm{P}=0,046)$ e predomínio de machos nos animais com $\mathrm{CMH}$.

Os parâmetros ecocardiográficos obtidos nos diferentes grupos estão descritos no Quadro 2. À avaliação das dimensões da raiz da aorta e do diâmetro do átrio esquerdo, sete gatos apresentaram relação $\mathrm{AE} /$ Ao maior que 1,5, indicati-
Quadro 1. Distribuição dos gatos Persa segundo peso corpóreo, idade e sexo. São Paulo, 2013

\begin{tabular}{ccccc}
\hline Gatos & Peso (kg) & Idade (meses) & Machos (\%) & Fêmeas (\%) \\
\hline Normais & $4,45 \pm 1,452$ & $58,79 \pm 41,118^{\mathrm{b}}$ & $31,48 \%^{\mathrm{a}}$ & $68,5 \%^{\mathrm{a}}$ \\
$(\mathrm{n}=54)$ & $(2,0-7,95)$ & $(11-156)$ & $(\mathrm{n}=17)$ & $(\mathrm{n}=37)$ \\
Suspeitos & $3,50 \pm 0,00$ & $29,83 \pm 13,37^{\mathrm{a}}$ & $50,00 \%$ & $50,00 \%$ \\
(n=6) & $(3,5)$ & $(10-52)$ & $(\mathrm{n}=3)$ & $(\mathrm{n}=3)$ \\
com CMH & $4,31 \pm 1,12$ & $77,59 \pm 46,63^{\mathrm{c}}$ & $68,18 \%^{\mathrm{b}}$ & $31,82 \%^{\mathrm{b}}$ \\
(n=22) & $(2,15-6,15)$ & $(19-168)$ & $(\mathrm{n}=15)$ & $(\mathrm{n}=7)$
\end{tabular}

$\overline{\mathrm{CMH}}=$ cardiomiopatia hipertrófica; $\mathrm{n}=$ número de animais; $\mathrm{a}, \mathrm{b}, \mathrm{c}$ indicadores de diferenças estatísticas.

Quadro 2. Média e desvio padrão de parâmetros ecocardiográficos em gatos da raça Persa. São Paulo, 2013

\begin{tabular}{lcccc}
\hline Parâmetros & $\begin{array}{c}\text { Todos } \\
(\mathrm{n}=82)\end{array}$ & $\begin{array}{c}\text { Normais } \\
(\mathrm{n}=54)\end{array}$ & $\begin{array}{c}\text { Suspeitos } \\
(\mathrm{n}=6)\end{array}$ & $\begin{array}{c}\mathrm{CMH} \\
(\mathrm{n}=22)\end{array}$ \\
\hline FC (bpm) & $192,17 \pm 30,73$ & $191,78 \pm 29,60$ & $171,00 \pm 31,26$ & $198,91 \pm 33,37$ \\
SIVAo (cm) & $0,51 \pm 0,04$ & $0,45 \pm 0,04$ & $0,49 \pm 0,06$ & $0,69 \pm 0,07$ \\
SIVd (cm) & $0,48 \pm 0,05$ & $0,43 \pm 0,04$ & $0,50 \pm 0,05$ & $0,60 \pm 0,08$ \\
PVEd (cm) & $0,44 \pm 0,05$ & $0,42 \pm 0,04$ & $0,44 \pm 0,04$ & $0,51 \pm 0,08$ \\
SIVd/PVEd & $1,08 \pm 0,08$ & $1,04 \pm 0,08$ & $1,14 \pm 0,12$ & $1,18 \pm 0,10$ \\
DVEd (cm) & $1,38 \pm 0,17$ & $1,41 \pm 0,17$ & $1,41 \pm 0,24$ & $1,31 \pm 0,17$ \\
DVEs (cm) & $0,63 \pm 0,14$ & $0,65 \pm 0,14$ & $0,68 \pm 0,19$ & $0,60 \pm 0,16$ \\
FS (\%) & $54,15 \pm 0,06$ & $54,00 \pm 0,06$ & $52,30 \pm 0,06$ & $55,00 \pm 0,08$ \\
Fej & $0,87 \pm 0,04$ & $0,87 \pm 0,04$ & $0,86 \pm 0,05$ & $0,88 \pm 0,07$ \\
Ao (cm) & $0,88 \pm 0,10$ & $0,88 \pm 0,11$ & $0,84 \pm 0,10$ & $0,91 \pm 0,10$ \\
AE (cm) & $1,13 \pm 0,19$ & $1,08 \pm 0,16^{\mathrm{a}}$ & $0,99 \pm 0,14^{\mathrm{a}}$ & $1,30 \pm 0,30^{\mathrm{b}}$ \\
AE/Ao & $1,28 \pm 0,17$ & $1,24 \pm 0,11^{\mathrm{a}}$ & $1,18 \pm 0,11^{\mathrm{a}}$ & $1,44 \pm 0,36^{\mathrm{b}}$ \\
Fl. Ao- Vmáx & $1,07 \pm 0,39$ & $0,94 \pm 0,25^{\mathrm{a}}$ & $0,92 \pm 0,14^{\mathrm{a}}$ & $1,44 \pm 0,81^{\mathrm{b}}$ \\
Fl. Ao- grad & $5,66 \pm 5,50$ & $3,76 \pm 2,16^{\mathrm{a}}$ & $3,47 \pm 1,00^{\mathrm{a}}$ & $10,94 \pm 14,94^{\mathrm{b}}$ \\
Fl. Pulm- Vmáx & $0,93 \pm 0,19$ & $0,93 \pm 0,19$ & $0,89 \pm 0,15$ & $0,97 \pm 0,22$ \\
Fl. Pulm- grad & $3,67 \pm 1,52$ & $3,60 \pm 1,41$ & $3,26 \pm 1,02$ & $3,96 \pm 1,94$ \\
Onda E (m/s) & $0,75 \pm 0,20$ & $0,75 \pm 0,18$ & $0,66 \pm 0,07$ & $0,78 \pm 0,29$ \\
TDE (ms) & $61,43 \pm 15,41$ & $59,51 \pm 14,22$ & $66,17 \pm 15,98$ & $64,86 \pm 18,21$ \\
Onda A (m/s) & $0,55 \pm 0,13$ & $0,54 \pm 0,14$ & $0,53 \pm 0,09$ & $0,61 \pm 0,14$ \\
E/A & $1,32 \pm 0,36$ & $1,36 \pm 0,31$ & $1,26 \pm 0,13$ & $1,25 \pm 0,54$ \\
TRIV (ms) & $46,43 \pm 6,37$ & $46,50 \pm 5,48$ & $49,67 \pm 6,16$ & $45,41 \pm 8,63$
\end{tabular}

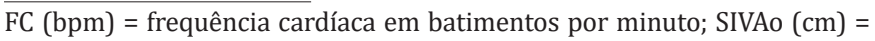
espessura diastólica do septo interventricular em região de via de saída do ventrículo esquerdo em centímetros; SIVd $(\mathrm{cm})=$ espessura diastólica do septo interventricular em centímetros; PVEd $(\mathrm{cm})=$ espessura diastólica da parede livre do ventrículo esquerdo em centímetros; DVEd $(\mathrm{cm})$ = diâmetro diastólico da cavidade do ventrículo esquerdo em centímetros; DVEs $(\mathrm{cm})=$ diâmetro sistólico da cavidade do ventrículo esquerdo em centímetros; FS (\%) = fração de encurtamento; Fej = fração de ejeção; Ao $(\mathrm{cm})$ = diâmetro da raiz da aorta, em centímetro, no corte transversal em modo bidimensional; $\mathrm{AE}(\mathrm{cm})=$ diâmetro do átrio esquerdo, em centímetro, no corte transversal em modo bidimensional; $\mathrm{AE} / \mathrm{Ao}$ = relação átrio esquerdo-aorta; Fl. Ao = fluxo aórtico; Vmáx (m/s) = velocidade máxima em metros por segundo; grad $(\mathrm{mmHg})=$ gradiente de pressão em milímetros de mercúrio; Fl. Pulm = fluxo na artéria pulmonar; TDE (ms) = tempo de desaceleração de onda E, em milissegundos; E/A = relação E/A; TRIV $(\mathrm{ms})$ = tempo de relaxamento isovolumétrico, em milissegundos; $\mathrm{CMH}$ = cardiomiopatia hipertrófica; $\mathrm{n}=$ número de animais; a,b indicadores de diferenças estatísticas.

va de aumento atrial $(8,53 \%)$, todos acometidos pela $\mathrm{CMH}$ (31,81\% dos gatos com $\mathrm{CMH})$. 0 aumento do átrio esquerdo foi considerado discreto em quatro gatos $(18,18 \%)$, moderado em dois $(9,09 \%)$ e importante em um animal com $\mathrm{CMH}(4,54 \%)$.

Dentre os indivíduos acometidos pela $\mathrm{CMH}$, hipertrofia miocárdica septal em região de via de saída do ventrículo esquerdo (SIVAo) ocorreu em 18 gatos $(81,82 \%)$ e, em quatro, observou-se hipertrofia miocárdica concêntrica $(18,18 \%)$. De acordo com a classificação de Wess et al. (2010), em 10 destes gatos acometidos, a CMH foi consi- 
Quadro 3. Parâmetros eletrocardiográficos em gatos da raça Persa. São Paulo, 2013

\begin{tabular}{|c|c|c|c|c|}
\hline Parâmetros & Todos (n=82) & Normais $(n=54)$ & Suspeitos $(n=6)$ & CMH $(n=22)$ \\
\hline \multicolumn{5}{|l|}{ Ritmo } \\
\hline RSN & $83,34 \%(n=68)$ & $83,64 \%(n=45)$ & $100 \%(n=6)$ & $78,26 \%(\mathrm{n}=17)$ \\
\hline TS & $9,52 \%(n=8)$ & $5,45 \%(n=3)$ & $0(n=0)$ & $21,74 \%(n=5)$ \\
\hline AS & $7,14 \%(n=6)$ & $10,91 \%(n=6)$ & $0(n=0)$ & $0(n=0)$ \\
\hline \multicolumn{5}{|l|}{ Bloqueios } \\
\hline Ausente & $73,82 \%(n=60)$ & $70,90 \%(n=38)$ & $100 \%(n=6)$ & $73,91 \%(n=16)$ \\
\hline BFAE & $10,71 \%(\mathrm{n}=9)$ & $10,91 \%(n=6)$ & $0(n=0)$ & $13,04 \%(n=3)$ \\
\hline BRD i & $9,52 \%(n=8)$ & $10,91 \%(n=6)$ & $0(n=0)$ & $8,70 \%(n=2)$ \\
\hline BRD & $3,57 \%(n=3)$ & $3,64 \%(n=2)$ & $0(n=0)$ & $4,35 \%(n=1)$ \\
\hline BAV de $1^{\circ}$ grau & $1,19 \%(\mathrm{n}=1)$ & $1,82 \%(\mathrm{n}=1)$ & $0(n=0)$ & $0(n=0)$ \\
\hline BRD i + BAV1음 & $1,19 \%(n=1)$ & $1,82 \%(n=1)$ & $0(n=0)$ & $0(n=0)$ \\
\hline \multicolumn{5}{|l|}{ Eixo elétrico } \\
\hline Normal & $69,06 \%(n=56)$ & $69,09 \%(n=37)$ & $83,33 \%(n=5)$ & $65,22 \%(n=14)$ \\
\hline Desvio à D & $15,47 \%(n=13)$ & $18,18 \%(n=10)$ & $0(n=0)$ & $13,04 \%(n=3)$ \\
\hline Desvio à E & $15,47 \%(n=13)$ & $12,73 \%(n=7)$ & $16,67 \%(\mathrm{n}=1)$ & $21,74 \%(n=5)$ \\
\hline \multicolumn{5}{|l|}{ Segmento ST } \\
\hline Normal & $98,81 \%(n=81)$ & $100 \%(n=54)$ & $100 \%(n=6)$ & $95,66 \%(n=21)$ \\
\hline Supradesnível & $1,19 \%(n=1)$ & $0(\mathrm{n}=0)$ & $0(n=0)$ & $4,34 \%(\mathrm{n}=1)$ \\
\hline Infradesnível & $0(n=0)$ & $0(\mathrm{n}=0)$ & $0(n=0)$ & $0(n=0)$ \\
\hline \multicolumn{5}{|l|}{ Onda T DII } \\
\hline Positiva & $95,24 \%(n=78)$ & $96,37 \%(n=52)$ & $83,34 \%(n=5)$ & $95,66 \%(n=21)$ \\
\hline Negativa & $4,76 \%(n=4)$ & $3,63 \%(n=2)$ & $16,66 \%(n=1)$ & $4,34 \%(n=1)$ \\
\hline \multicolumn{5}{|l|}{ Onda T CV5RL } \\
\hline Positiva & $100 \%(n=82)$ & $100 \%(n=54)$ & $100 \%(n=6)$ & $100 \%(n=22)$ \\
\hline \multicolumn{5}{|l|}{ Onda T CV6LL } \\
\hline Positiva & $97,62 \%(n=80)$ & $100 \%(\mathrm{n}=54)$ & $100 \%(n=6)$ & $91,31 \%(n=20)$ \\
\hline Negativa & $2,38 \%(n=2)$ & $0(n=0)$ & $0(n=0)$ & $8,69 \%(n=2)$ \\
\hline \multicolumn{5}{|l|}{ Onda T CV6LU } \\
\hline Positiva & $95,24 \%(n=78)$ & $98,19 \%(n=53)$ & $100 \%(n=6)$ & $86,96 \%(n=19)$ \\
\hline Negativa & $4,76 \%(n=4)$ & $1,81 \%(\mathrm{n}=1)$ & $0(n=0)$ & $13,04 \%(n=3)$ \\
\hline \multicolumn{5}{|l|}{ QRS V10 } \\
\hline Positivo & $72,62 \%(n=59)$ & $74,55 \%(\mathrm{n}=40)$ & $83,34 \%(n=5)$ & $65,22 \%(n=14)$ \\
\hline Negativo & $27,38 \%(n=23)$ & $25,45 \%(n=14)$ & $16,66 \%(n=1)$ & $34,78 \%(n=8)$ \\
\hline \multicolumn{5}{|l|}{ Onda T V10 } \\
\hline Positiva & $75,00 \%(n=61)$ & $74,551 \%(n=40)$ & $66,67 \%(n=4)$ & $78,27 \%(\mathrm{n}=17)$ \\
\hline Negativa & $25,00 \%(n=21)$ & $25,45 \%(n=14)$ & $33,33 \%(n=2)$ & $21,73 \%(n=5)$ \\
\hline
\end{tabular}

$\mathrm{RSN}=$ ritmo sinusal normal; $\mathrm{AS}=$ arritmia sinusal; $\mathrm{TS}=$ taquicardia sinusal; $\mathrm{BFAE}=$ bloqueio de fascículo anterior esquerdo; $\mathrm{BRD} \mathrm{i}=$ bloqueio de ramo direito incompleto; $\mathrm{BRD}=$ bloqueio de ramo direito; $\mathrm{BAV}=$ bloqueio atrioventricular; $\mathrm{D}=$ direita; $\mathrm{E}=$ esquerda; $\mathrm{CMH}=$ cardiomiopatia hipertrófica; $\mathrm{n}=$ número de animais.

derada de grau discreto (45,47\%); de grau moderado em outros nove $(40,90 \%)$; e de grau importante em três gatos $(13,63 \%)$.

Foram observadas diferenças estatísticas em relação à velocidade e ao gradiente de pressão do fluxo aórtico $(\mathrm{P}=0,006$ e $\mathrm{P}=0,032$, respectivamente), com valores superiores nos gatos com $\mathrm{CMH}$. 0 diâmetro do átrio esquerdo e a relação $\mathrm{AE} / \mathrm{Ao}$ foram significativamente superiores nos gatos com CMH em relação aos normais $(\mathrm{P}=0,008$ e $\mathrm{P}=0,023$, respectivamente).

Ao exame eletrocardiográfico, o ritmo mais frequente foi o ritmo sinusal normal, seguido da taquicardia sinusal e arritmia sinusal (Quadro 3). Apenas um gato com $\mathrm{CMH}$ apresentou complexos ventriculares prematuros (VPCs) isolados e polimórficos durante a monitorização $(1,21 \%)$. Dentre os distúrbios de condução e bloqueios, observaram-se bloqueio de ramo direito (BRD) completo e incompleto, bloqueio de fascículo anterior esquerdo (BFAE) e bloqueio atrioventricular de primeiro grau (Quadro 3), não havendo diferenças estatísticas em relação à sua ocorrência nos grupos avaliados. Os parâmetros eixo cardíaco elétrico, pola- ridade de onda $\mathrm{T}$ nas diferentes derivações e segmento ST também estão descritos no Quadro 3.

Como o objetivo do presente trabalho foi avaliar a sensibilidade e a especificidade do exame eletrocardiográfico em identificar sobrecargas atriais e/ou ventriculares e isto requer análise de amplitude e duração das ondas eletrocardiográficas, os gatos com alterações de condução e bloqueios (BRD completo e incompleto, BFAE e/ou bloqueio atrioventricular) foram excluídos da análise estatística. Desta forma, 22 animais foram excluídos da comparação ecocardiográfica e eletrocardiográfica por apresentarem essas alterações de condução e/ou bloqueios. Os parâmetros ecocardiográficos e eletrocardiográficos como frequência cardíaca, largura e amplitude da onda P, intervalo PR, largura do complexo QRS, amplitude de onda R, intervalo QT e amplitude das ondas $\mathrm{R}$ e $\mathrm{S}$ nas derivações precordiais CV5RL (rV2), CV6LL (V2) e CV6LU (V4), nos diferentes grupos (38 gatos normais, seis suspeitos e 16 acometidos pela $\mathrm{CMH}$, totalizando 60 animais), estão descritos nos Quadros 4 e 5 , respectivamente.

Dos sessenta animais avaliados, apenas um (acometido 
Quadro 4. Média e desvio padrão de parâmetros ecocardiográficos em gatos da raça Persa (animais sem alterações de condução e/ou bloqueios no eletrocardiograma), São Paulo, 2013

\begin{tabular}{|c|c|c|c|c|}
\hline Parâmetros & $\begin{array}{c}\text { Todos } \\
(n=60)\end{array}$ & $\begin{array}{c}\text { Normais } \\
(n=38)\end{array}$ & $\begin{array}{c}\text { Suspeitos } \\
(\mathrm{n}=06)\end{array}$ & $\begin{array}{c}\text { CMH } \\
(n=16)\end{array}$ \\
\hline $\mathrm{FC}(\mathrm{bpm})$ & $191,98 \pm 30,37$ & $192,42 \pm 28,28$ & $171,00 \pm 31,26$ & $198,81 \pm 31,32$ \\
\hline SIVAo $(\mathrm{cm})$ & $0,52 \pm 0,11$ & $0,45 \pm 0,04$ & $0,49 \pm 0,06$ & $0,68 \pm 0,07$ \\
\hline SIVd $(\mathrm{cm})$ & $0,48 \pm 0,09$ & $0,43 \pm 0,04$ & $0,50 \pm 0,05$ & $0,61 \pm 0,07$ \\
\hline PVEd $(\mathrm{cm})$ & $0,45 \pm 0,07$ & $0,41 \pm 0,04$ & $0,44 \pm 0,04$ & $0,53 \pm 0,09$ \\
\hline SIVd/PVEd & $1,08 \pm 0,09$ & $1,04 \pm 0,07$ & $1,14 \pm 0,12$ & $1,16 \pm 0,07$ \\
\hline DVEd $(\mathrm{cm})$ & $1,38 \pm 0,19$ & $1,40 \pm 0,17$ & $1,41 \pm 0,24$ & $1,31 \pm 0,18$ \\
\hline DVEs $(\mathrm{cm})$ & $0,62 \pm 0,15$ & $0,63 \pm 0,14$ & $0,68 \pm 0,19$ & $0,57 \pm 0,15$ \\
\hline FS (\%) & $55,00 \pm 0,07$ & $55,00 \pm 0,06$ & $52,30 \pm 0,06$ & $57,00 \pm 0,07$ \\
\hline Fej & $0,88 \pm 0,05$ & $0,88 \pm 0,05$ & $0,86 \pm 0,05$ & $0,89 \pm 0,06$ \\
\hline Ao $(\mathrm{cm})$ & $0,88 \pm 0,11$ & $0,88 \pm 0,12$ & $0,84 \pm 0,10$ & $0,90 \pm 0,10$ \\
\hline $\mathrm{AE}(\mathrm{cm})$ & $1,13 \pm 0,25$ & $1,08 \pm 0,17 \mathrm{a}$ & $0,99 \pm 0,14 \mathrm{a}$ & $1,30 \pm 0,33 \mathrm{~b}$ \\
\hline $\mathrm{AE} / \mathrm{Ao}$ & $1,28 \pm 0,24$ & $1,24 \pm 0,12 \mathrm{a}$ & $1,18 \pm 0,11 \mathrm{a}$ & $1,44 \pm 0,37 \mathrm{~b}$ \\
\hline Fl. Ao- Vmáx & $1,02 \pm 0,46$ & $0,92 \pm 0,24 \mathrm{a}$ & $0,92 \pm 0,14 \mathrm{a}$ & $1,31 \pm 0,75 \mathrm{~b}$ \\
\hline Fl. Ao-grad & $5,07 \pm 7,98$ & $3,63 \pm 1,98 \mathrm{a}$ & $3,47 \pm 1,00 \mathrm{a}$ & $9,08 \pm 14,39 b$ \\
\hline Fl. Pulm-Vmáx & $0,95 \pm 0,20$ & $0,93 \pm 0,21$ & $0,89 \pm 0,15$ & $1,00 \pm 0,21$ \\
\hline Fl. Pulm-grad & $3,75 \pm 1,65$ & $3,66 \pm 1,56$ & $3,26 \pm 1,02$ & $4,15 \pm 1,95$ \\
\hline Onda E (m/s) & $0,74 \pm 0,24$ & $0,73 \pm 0,19$ & $0,66 \pm 0,07$ & $0,78 \pm 0,34$ \\
\hline TDE (ms) & $64,04 \pm 14,56$ & $62,57 \pm 12,05$ & $66,17 \pm 15,98$ & $66,75 \pm 18,46$ \\
\hline Onda A (m/s) & $0,55 \pm 0,14$ & $0,54 \pm 0,15$ & $0,53 \pm 0,09$ & $0,60 \pm 0,13$ \\
\hline $\mathrm{E} / \mathrm{A}$ & $1,30 \pm 0,40$ & $1,33 \pm 0,32$ & $1,26 \pm 0,13$ & $1,22 \pm 0,58$ \\
\hline TRIV (ms) & $46,67 \pm 6,89$ & $46,32 \pm 5,41$ & $49,67 \pm 6,16$ & $46,38 \pm 9,51$ \\
\hline
\end{tabular}

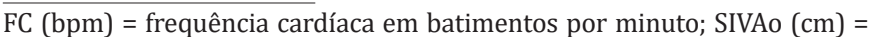
espessura diastólica do septo interventricular em região de via de saída do ventrículo esquerdo em centímetros; SIVd $(\mathrm{cm})$ = espessura diastólica do septo interventricular em centímetros; PVEd $(\mathrm{cm})=$ espessura diastólica da parede livre do ventrículo esquerdo em centímetros; DVEd $(\mathrm{cm})=$ diâmetro diastólico da cavidade do ventrículo esquerdo em centímetros; DVEs $(\mathrm{cm})=$ diâmetro sistólico da cavidade do ventrículo esquerdo em centímetros; FS $(\%)$ = fração de encurtamento; Fej = fração de ejeção; Ao $(\mathrm{cm})$ = diâmetro da raiz da aorta, em centímetro, no corte transversal em modo bidimensional; $\mathrm{AE}(\mathrm{cm})=$ diâmetro do átrio esquerdo, em centímetro, no corte transversal em modo bidimensional; $\mathrm{AE} / \mathrm{Ao}$ = relação átrio esquerdo-aorta; Fl. Ao = fluxo aórtico; Vmáx (m/s) = velocidade máxima em metros por segundo; $\operatorname{grad}(\mathrm{mmHg})=$ gradiente de pressão em milímetros de mercúrio; Fl. Pulm = fluxo na artéria pulmonar; TDE (ms) = tempo de desaceleração de onda E, em milissegundos; $\mathrm{E} / \mathrm{A}$ = relação $\mathrm{E} / \mathrm{A} ; \mathrm{TRIV}$ (ms) = tempo de relaxamento isovolumétrico, em milissegundos; $\mathrm{CMH}=$ cardiomiopatia hipertrófica; $\mathrm{n}=$ número de animais; a,b indicadores de diferenças estatísticas.

pela $\mathrm{CMH}$ ) apresentou distúrbio de repolarização ventricular, com supradesnível de ST de 0,2 mV (1,66\%). Os parâmetros eletrocardiográficos foram sugestivos de sobrecarga de átrio esquerdo (onda P com duração superior a 0,04 s em derivação DII) em sete gatos (11,66\%), dos quais um era normal, dois eram suspeitos e quatro com CMH. Alterações eletrocardiográficas sugestivas de sobrecarga ventricular esquerda (complexo QRS com duração superior a $0,04 \mathrm{~s}$; onda $\mathrm{R}$ com amplitude superior a $0,9 \mathrm{mV}$ em derivação DII; e/ou onda R com amplitude superior a 1,0 mV em derivações precordiais CV6LL e/ou CV6LU) foram observadas em seis animais (10,0\%), dos quais um era suspeito e cinco apresentavam $\mathrm{CMH}$.

A amplitude da onda P em derivação DII foi significativamente maior nos gatos com $\mathrm{CMH}(\mathrm{P}=0,001)$; e a amplitude da onda R em derivação DII e em precordiais CV6LL e CV6LU foi significativamente maior nos animais com $\mathrm{CMH}$ $(\mathrm{P}=0,006, \mathrm{P}=0,010$ e $\mathrm{P}=0,029$, respectivamente). Não foram observadas diferenças estatísticas nos demais parâmetros eletrocardiográficos avaliados.

Dos gatos com parâmetros eletrocardiográficos su-
Quadro 5. Média e desvio padrão de parâmetros eletrocardiográficos de gatos da raça Persa (sem alterações de condução e/ou bloqueios no eletrocardiograma). São Paulo, 2013

\begin{tabular}{lcccc}
\hline Parâmetros & $\begin{array}{c}\text { Todos } \\
(\mathrm{n}=60)\end{array}$ & $\begin{array}{c}\text { Normais } \\
(\mathrm{n}=38)\end{array}$ & $\begin{array}{c}\text { Suspeitos } \\
(\mathrm{n}=6)\end{array}$ & $\begin{array}{c}\text { CMH } \\
(\mathrm{n}=16)\end{array}$ \\
\hline FC (bpm) & $192,52 \pm 27,484$ & $191,30 \pm 28,838$ & $176,67 \pm 9,428$ & $201,38 \pm 31,041$ \\
P (s) & $0,03 \pm 0,008$ & $0,03 \pm 0,008$ & $0,04 \pm 0,015$ & $0,04 \pm 0,009$ \\
P (mV) & $0,14 \pm 0,042$ & $0,13 \pm 0,043^{\mathrm{a}}$ & $0,16 \pm 0,037^{\mathrm{a}}$ & $0,19 \pm 0,045^{\mathrm{b}}$ \\
PR (s) & $0,07 \pm 0,007$ & $0,07 \pm 0,008$ & $0,07 \pm 0,005$ & $0,07 \pm 0,008$ \\
QRS (s) & $0,02 \pm 0,006$ & $0,02 \pm 0,006$ & $0,03 \pm 0,004$ & $0,03 \pm 0,007$ \\
R (mV) & $0,34 \pm 0,178$ & $0,27 \pm 0,139^{\mathrm{a}}$ & $0,36 \pm 0,182^{\mathrm{a}}$ & $0,50 \pm 0,271^{\mathrm{b}}$ \\
QT (s) & $0,14 \pm 0,016$ & $0,14 \pm 0,018$ & $0,16 \pm 0,009$ & $0,14 \pm 0,015$ \\
R CV5RL (mV) & $0,24 \pm 0,143$ & $0,21 \pm 0,121$ & $0,30 \pm 0,261$ & $0,31 \pm 0,151$ \\
S CV5RL (mV) & $0,20 \pm 0,178$ & $0,16 \pm 0,119$ & $0,28 \pm 0,147$ & $0,28 \pm 0,330$ \\
R CV6LL (mV) & $0,33 \pm 0,220$ & $0,24 \pm 0,134$ & $0,38 \pm 0,366$ & $0,53 \pm 0,370$ \\
S CV6LL (mV) & $0,11 \pm 0,124$ & $0,12 \pm 0,134$ & $0,16 \pm 0,124$ & $0,08 \pm 0,103$ \\
R CV6LU (mV) & $0,27 \pm 0,209$ & $0,19 \pm 0,121^{\mathrm{a}}$ & $0,30 \pm 0,217^{\mathrm{a}}$ & $0,45 \pm 0,416^{\mathrm{b}}$ \\
S CV6LU (mV) & $0,04 \pm 0,062$ & $0,05 \pm 0,068$ & $0,05 \pm 0,045$ & $0,03 \pm 0,056$
\end{tabular}

$\mathrm{FC}$ = frequência cardíaca; $\mathrm{P}(\mathrm{s})$ = largura de onda $\mathrm{P} ; \mathrm{P}(\mathrm{mV})$ = amplitude de onda P; PR (s) = intervalo PR; QRS (s) = largura do complexo QRS; R (mV) = amplitude da onda R; QT (s) = intervalo QT; R CV5RL (mV) = amplitude da onda R em CV5RL; S CV5RL (mV) = amplitude da onda S em CV5RL; R CV6LL (mV) = amplitude da onda R em CV6LL; S CV6LL (mV) = amplitude da onda S em CV6LL; R CV6LU (mV) = amplitude da onda R em CV6LU; $\mathrm{S}$ CV6LU $(\mathrm{mV})=$ amplitude da onda $\mathrm{S}$ em C6LU; $(\mathrm{s})=$ segundos; $(\mathrm{mV})=$ milivolts; $\mathrm{CMH}$ = cardiomiopatia hipertrófica; $\mathrm{n}=$ número de animais, $\mathrm{a}, \mathrm{b}$ indicadores de diferenças estatísticas.

gestivos de sobrecarga atrial esquerda $(n=7)$, apenas dois com $\mathrm{CMH}$ realmente apresentavam aumento de átrio esquerdo ao ecocardiograma. Por outro lado, dentre os gatos com aumento atrial esquerdo detectado ao ecocardiograma (excluindo-se aqueles com bloqueios ou alterações de condução no ECG) $(n=5)$, apenas dois apresentaram alterações eletrocardiográficas sugestivas de sobrecarga atrial esquerda. Desta forma, a sensibilidade do ECG em detectar aumento de AE foi de $40,00 \%$ e a especificidade foi de $90,90 \%$, com acurácia de $86,66 \%$, valor preditivo positivo (VPP) de $28,57 \%$ e valor preditivo negativo (VPN) de $94,33 \%$. A razão de probabilidade positiva (RPP) foi de 4,400 e a razão de probabilidade negativa (RPN) foi de 0,660 . Não se observou correlação entre a duração da onda $\mathrm{P}$ do eletrocardiograma e a relação AE/Ao do ecocardiograma.

Dentre os animais com parâmetros eletrocardiográficos sugestivos de sobrecarga ventricular esquerda $(n=6)$, cinco realmente apresentavam aumento da espessura do septo interventricular e/ou da parede livre do VE ao ecocardiograma (quadro condizente com $\mathrm{CMH}$ ). Por outro lado, de todos os gatos com $\mathrm{CMH}$ detectada ao ecocardiograma $(n=16)$, apenas cinco apresentaram alterações eletrocardiográficas sugestivas de sobrecarga ventricular esquerda. Desta forma, a sensibilidade do ECG em detectar sobrecarga ventricular esquerda foi de $31,25 \%$ e a especificidade foi de 97,72\%, com acurácia de 80\% (VPP de 83,33\% e VPN de $79,62 \%$ ). A (RPP) foi de 13,754 e a razão de probabilidade negativa (RPN) foi de 0,703 .

Na avaliação de possíveis correlações entre parâmetros eletrocardiográficos e ecocardiográficos, observou-se correlação positiva entre amplitude da onda R (em DII) e espessura diastólica do septo interventricular em região 
de via de saída do ventrículo esquerdo (SIVao) $(\mathrm{P}=0,0007$, rho=0,423); amplitude da onda R (em DII) e SIVd ( $\mathrm{P}=0,007$, rho=0,339); amplitude da onda $\mathrm{R}$ (em DII) e PVEd $(\mathrm{P}=0,001$, rho=0,393); amplitude da onda $\mathrm{R}$ (em CV6LU) e SIVao $(\mathrm{P}=0,0004$, rho=0,528); amplitude da onda $\mathrm{R}$ (em CV6LU) e SIVd ( $\mathrm{P}=0,001, \mathrm{rho}=0,489)$, amplitude da onda $\mathrm{R}$ (em CV6LU) e PVEd $(\mathrm{P}=0,014$, rho=0,379).

\section{DISCUSSÃO}

A população avaliada foi composta por gatos da raça Persa, machos e fêmeas, procedentes de criatórios comerciais. Dos 100 gatos inicialmente avaliados, 22 apresentaram diagnóstico ecocardiográfico de cardiomiopatia hipertrófica, correspondendo a uma prevalência de $22 \%$ na população de estudo. De acordo com Kittleson et al. (1999), Chetboul et al. (2006) e McDonald et al. (2007), a CMH é a principal cardiopatia causadora de mortalidade e morbidade nos felinos. Em humanos, estima-se que a prevalência seja de um a cada 500 indivíduos (Mattos et al. 2013); em gatos, a prevalência descrita varia de $8,5 \%$ (Granström et al. 2011) a 41,5\% (Paige et al. 2009), com diferenças de acordo com o padrão racial avaliado. No presente trabalho, seis gatos $(7,31 \%)$, foram considerados suspeitos para a CMH. De acordo com a literatura, a CMH é uma doença miocárdica genética e fenotipicamente heterogênea caracterizada por aumento na massa ventricular esquerda, tanto pelo aumento na espessura da parede quanto pelo desarranjo histológico de miócitos e miofibrilas, e o diagnóstico nem sempre é fácil (Wess et al. 2010).

A distribuição de machos e fêmeas na população estudada foi homogênea. Porém, a proporção de machos entre os acometidos pela $\mathrm{CMH}$ foi significativamente maior $(68,18 \%)$. Segundo autores, a CMH é mais relatada em machos de meia idade, mas também pode ocorrer em fêmeas, em jovens ou idosos (Chetboul et al. 2006, McDonald et al. 2007). Alguns estudos não referem diferenças quanto ao sexo, mas há relatos de manifestações precoces e mais evidentes nos machos (Ware 2007).

A média do peso dos machos foi maior que a das fêmeas, o que pode ser justificado pelo padrão racial dos animais, onde machos são visivelmente maiores que fêmeas. A média de idade dos animais com CMH foi significativamente superior à dos suspeitos e dos normais. De acordo com Trehiou-Sechi et al. (2012), em gatos Persas a CMH é mais diagnosticada em animais mais velhos, com média de 11 anos de idade ao diagnóstico, padrão diferente do encontrado em outras raças, como Maine Coon e Ragdoll.

Como o objetivo do presente trabalho era avaliar a sensibilidade e a especificidade do exame eletrocardiográfico em identificar sobrecargas atriais e/ou ventriculares e isto requer análise de amplitude e duração das ondas eletrocardiográficas (Tilley 1992), os gatos com alterações de condução e bloqueios de ramo direito (BRD completo e incompleto), bloqueio fascicular anterior esquerdo (BFAE) e/ou bloqueio atrioventricular (BAV) foram excluídos da análise estatística. Desta forma, dentre todos os animais avaliados, foram selecionados para o estudo (após critérios de exclusão) 60 gatos (38 normais, seis suspeitos e 16 com CMH). A comparação entre parâmetros ecocardiográficos e eletro- cardiográficos foi realizada entre estes animais $(n=60)$.

À avaliação ecocardiográfica, o diâmetro do $\mathrm{AE}$ e a relação $\mathrm{AE} / \mathrm{Ao}$ foram maiores nos gatos acometidos pela CMH em relação aos suspeitos e aos normais. Observaram-se diferenças na velocidade e no gradiente de pressão do fluxo aórtico, que foram maiores nos acometidos quando comparados aos animais normais. Dentre os animais com $\mathrm{CMH}$, a hipertrofia miocárdica septal em região de via de saída do ventrículo esquerdo (SIVAo) ocorreu em 81,82\% dos casos. Segundo a literatura, o ecocardiograma é o melhor meio diagnóstico não invasivo para a diferenciação de $\mathrm{CMH}$ de outras cardiomiopatias e permite caracterizar anormalidades funcionais (Chetboul et al. 2006, Gundler et al. 2008). 0 átrio aumenta de tamanho, às vezes de forma acentuada, mas o volume ventricular esquerdo permanece normal ou diminuído (Gundler et al. 2008, Ferasin 2009). De acordo com Trehiou-Sechi et al. (2012), em gatos Persas, a forma mais comum da CMH é a hipertrofia miocárdica septal, compatível com os achados do presente trabalho e que também pode justificar o maior gradiente de pressão e velocidade do fluxo aórtico nos animais acometidos.

À avaliação eletrocardiográfica, os valores de amplitude de onda R na derivação DII e nas precordiais CV6LL e CV6LU foram maiores nos gatos acometidos pela CMH em relação aos normais. Segundo Tilley (1992), amplitude da onda R superior a 0,9 mV em derivação DII e superior a 1,0 $\mathrm{mV}$ em precordiais CV6LL e CV6LU em gatos são alterações eletrocardiográficas sugestivas de sobrecarga ventricular (concêntrica ou excêntrica). Apesar dos valores de amplitude de onda $\mathrm{R}$ nestas diferentes derivações serem superiores nos gatos com CMH em relação aos demais, nem todos os gatos com $\mathrm{CMH}$ avaliados no trabalho apresentaram amplitudes acima do valor de referência para a espécie. De acordo com Bacharova (2009), Bender et al. (2012) e Rowin et al. (2012), o ECG apresenta baixa sensibilidade na detecção de sobrecargas e há baixa correlação entre a amplitude do QRS e o grau de hipertrofia. Porém, o ECG apresenta boa especificidade no diagnóstico de hipertrofia ventricular em humanos (Lakdawala et al. 2011).

Apesar do exame ecocardiográfico demonstrar diferença estatística em relação ao tamanho do átrio esquerdo (significativamente maior nos gatos com $\mathrm{CMH}$ ), não foram observadas diferenças eletrocardiográficas em relação à duração da onda P (que poderia sugerir sobrecarga atrial esquerda) nos diferentes grupos. Resultados semelhantes já foram demonstrados por Moise et al. (1986), em que o eletrocardiograma foi um pobre indicador de sobrecarga atrial nos gatos. No presente trabalho, observou-se amplitude da onda P significativamente maior nos animais com CMH quando comparados com os normais. Porém, nenhum gato apresentou sobrecarga atrial direita ao ecocardiograma e nenhum animal apresentou alterações eletrocardiográficas que sugerissem aumento atrial direito (a amplitude da onda P estava dentro da normalidade em todos os animais).

Sete gatos tinham parâmetros eletrocardiográficos sugestivos de sobrecarga atrial esquerda, mas apenas dois apresentavam, realmente, aumento de $\mathrm{AE}$ ao ecocardiograma. Por outro lado, dos cinco gatos com aumento atrial 
esquerdo confirmado pelo ecocardiograma, apenas dois apresentaram alterações eletrocardiográficas sugestivas de sobrecarga atrial esquerda. Desta forma, a sensibilidade do ECG em detectar aumento de AE foi de $40,00 \%$ e a especificidade foi de 90,90\%, com acurácia de 86,66\%. De acordo com Moise et al. (1986), o eletrocardiograma não é um exame sensível para detectar aumento de $\mathrm{AE}$ em gatos; e Schober et al. (2007) encontraram resultados com baixa sensibilidade mas boa especificidade, à semelhança dos resultados deste trabalho. Além da baixa sensibilidade e da especificidade média a alta do ECG em detectar aumento de $\mathrm{AE}$, não foi observada correlação entre a duração de onda $P$ do eletrocardiograma e a relação $\mathrm{AE} / \mathrm{Ao}$ do ecocardiograma, diferentemente de outros trabalhos citados na literatura veterinária (Schober et al. 2007) e humana (Ryan et al. 1995, Namdar et al. 2012), onde houve correlação positiva entre onda $\mathrm{P}$ e tamanho atrial esquerdo.

A razão de probabilidade (também interpretável como razão de verossimilhança) pode ser utilizada para determinar o valor de um teste diagnóstico e é expressa em chances (Siegel \& Castellan 1988, Neter et al. 1996). Estas razões expressam quantas vezes mais provável (ou menos) se encontra um resultado de um teste em indivíduos doentes comparado com os não doentes. Quanto maior a (RPP), melhor o teste (é mais provável do resultado ser verdadeiro positivo do que falso-positivo); e quanto menor a razão de probabilidade negativa (RPN), melhor o teste (é mais provável de ser um verdadeiro resultado negativo do que um falso-negativo) (Siegel \& Castellan 1988, Neter et al. 1996). No presente trabalho, a RPP para avaliação de sobrecarga atrial esquerda pelo ECG foi de 4,4 e a RPN de 0,66. Desta forma, a chance do ECG detectar sobrecarga de AE em indivíduos que realmente tenham aumento de $\mathrm{AE}$ é 4,4 vezes maior que a chance de detectar sobrecarga de $\mathrm{AE}$ em indivíduos que não apresentam o aumento. Por outro lado, a chance do ECG não detectar sobrecarga de AE em indivíduos que possuem aumento do $\mathrm{AE}$ é 0,66 vezes a chance de não detectar sobrecarga de $\mathrm{AE}$ em indivíduos que realmente não possuem aumento.

Seis gatos apresentaram parâmetros eletrocardiográficos sugestivos de sobrecarga ventricular esquerda e, destes, cinco realmente apresentavam aumento da espessura do septo interventricular e/ou da parede livre do ventrículo esquerdo ao ecocardiograma (quadro condizente com $\mathrm{CMH}$ ). Porém, dos 16 gatos com $\mathrm{CMH}$ diagnosticada ao ecocardiograma, apenas cinco apresentaram alterações eletrocardiográficas sugestivas de sobrecarga ventricular esquerda. Desta forma, a sensibilidade do ECG em detectar sobrecarga ventricular esquerda foi de $31,25 \%$ e a especificidade de 97,72\%, com acurácia de 80\%. De acordo com Lakdawala et al. (2011), o ECG apresenta boa especificidade mas baixa sensibilidade em detectar aumentos ventriculares. Em humanos, o diagnóstico eletrocardiográfico de hipertrofia ventricular é baseado no aumento da voltagem dos complexos QRS em diferentes derivações (Murphy et al. 1985, Konno et al. 2005, Bacharova 2009); e a combinação destes critérios pode aumentar a sensibilidade do método, permitindo seu uso como exame de triagem com maior segurança. Em gatos, poucos estudos foram realizados quan- to à sensibilidade e especificidade do ECG na detecção de hipertrofia ventricular. Moise et al. (1985) constataram que o ECG indicou incorretamente aumento ventricular em gatos com hipertireoidismo e não detectou consistentemente a ocorrência de sobrecarga ventricular em pacientes com $\mathrm{CMH}$, mostrando a baixa sensibilidade do ECG para esta finalidade.

A RPP para avaliação de sobrecarga ventricular esquerda pelo ECG foi de 13,754 e a RPN foi de 0,703. Desta forma, a chance do ECG detectar sobrecarga ventricular esquerda em indivíduos que realmente tenham hipertrofia é 13,754 vezes maior que a chance de detectar sobrecarga ventricular esquerda em indivíduos sem aumento. Por outro lado, a chance do ECG não detectar sobrecarga ventricular esquerda em indivíduos com hipertrofia é 0,703 vezes a chance de não detectar sobrecarga ventricular esquerda em indivíduos sem aumento. Desta forma, o ECG apresenta boa especificidade na detecção de hipertrofia ventricular.

Observou-se correlação positiva entre amplitude da onda R (em DII) e SIVao ( $\mathrm{P}=0,0007$, rho=0,423); amplitude da onda R (em DII) e SIVd $(\mathrm{P}=0,007$, rho=0,339); amplitude da onda R (em DII) e PVEd ( $\mathrm{P}=0,001$, rho $=0,393)$; amplitude da onda $\mathrm{R}$ (em CV6LU) e SIVao ( $\mathrm{P}=0,0004$, rho=0,528); amplitude da onda $\mathrm{R}$ (em CV6LU) e SIVd $(\mathrm{P}=0,001$, rho=0,489), amplitude da onda $\mathrm{R}$ (em CV6LU) e PVEd $(\mathrm{P}=0,014$, rho=0,379). De acordo com Tilley (1992), quanto maior a hipertrofia ventricular (seja excêntrica ou concêntrica), maiores os valores de amplitude de onda $\mathrm{R}$ e duração dos complexos QRS ao ECG. No entanto, alguns estudos revelam baixa correlação positiva entre a amplitude do QRS e o grau de hipertrofia ventricular (Bacharova 2009, Bender et al. 2012, Rowin et al. 2012), à semelhança do encontrado no estudo atual.

Apesar do exame eletrocardiográfico não permitir diagnóstico preciso de hipertrofia de VE neste estudo, alterações eletrocardiográficas sugestivas de sobrecarga ventricular foram bastante consistentes com CMH (especificidade de 97,72\%). A ausência de alterações no ECG não exclui a $\mathrm{CMH}$, mas a presença das alterações aumenta bastante a suspeita de $\mathrm{CMH}$ nesses animais. 0 mesmo não é válido para sobrecargas atriais (sensibilidade e especificidade baixas). Segundo Bacharova (2009), Bender et al. (2012) e Rowin et al. 2012, apesar da baixa sensibilidade do ECG em detectar sobrecarga do VE, a ocorrência de alterações eletrocardiográficas que sugerem hipertrofia ventricular pode ser considerada um marcador prognóstico e de gravidade, permitindo estratificação de risco desses pacientes. De acordo com Killian et al. (2010), devido ao baixo valor preditivo positivo do ECG em detectar hipertrofia, pode haver necessidade de confirmação ecocardiográfica, principalmente, em indivíduos mais jovens. A habilidade do ECG em estimar a hipertrofia ventricular é baixa e os argumentos a favor de seu uso como ferramenta diagnóstica na $\mathrm{CMH}$ estão relacionados ao baixo custo e boa disponibilidade do método (Bacharova 2009, Rowin et al. 2012).

As principais limitações deste estudo referem-se ao pequeno número de animais analisados. Devido à exclusão dos gatos que apresentaram bloqueios e/ou alterações de condução ao exame eletrocardiográfico, a avaliação 
limitou-se a 60 gatos. Outra limitação foi a realização dos exames nos gatis. 0 ambiente nem sempre foi o ideal para a realização dos exames complementares e muitos animais foram excluídos da avaliação devido a interferências no traçado eletrocardiográfico. Além disso, a avaliação em criatórios comerciais pode ter selecionado indivíduos mais jovens e inteiros (finalidade reprodutiva), o que não necessariamente representaria a população real de gatos Persas.

\section{CONCLUSÕES}

De acordo com o presente estudo, o eletrocardiograma é um exame rápido e de fácil execução, apresenta boa especificidade na detecção da hipertrofia ventricular em felinos, porém, possui baixa sensibilidade, com grande número de animais falsos-negativos.

Desta forma, o ECG auxilia no diagnóstico, mas não substitui o ecocardiograma na confirmação da hipertrofia ventricular.

Agradecimentos.- À Fundação de Amparo à Pesquisa do Estado de São Paulo (FAPESP) pelo Auxílio Pesquisa concedido (proc 12/04990-2); aos criadores de gatos da raça Persa e respectivos gatis do estado de São Paulo que participaram da pesquisa; ao Centro de Diagnóstico e Especialidades Provet, pela realização da dosagem do T4 total.

\section{REFERÊNCIAS}

Abbott J.A. \& McLean H.N. 2006.Two-dimensional echocardiographic assessment of the feline left atrium. J. Vet. Intern. Med. 20:111-119.

Bacharova L. 2009. Electrocardiography- left ventricular mass discrepancies in left ventricular hypertrophy: electrocardiography imperfection or beyond perfection? J. Electr. 42:593-96.

Bender S.R., Friedman D.J., Markowitz S.M., Lerman B.B. \& Okin P.M. 2012. Electrocardiographic left ventricular hypertrophy predicts arrhythmia and mortality in patients with ischemic cardiomyopathy. J. Interv. Card. Electrophysiol. 34:237-245.

Boon J.A. 2011. Manual of Veterinary Echocardiography. Wiley-Blackwell, West Sussex. 610p.

Brown S., Atkins C., Bagley R., Carr A., Cowgill L., Davidson M., Egner B., Elliott J., Henik R., Labato M., Littman M., Polzin D., Ross L., Snyder P. \& Stepien R. 2007. Guidelines for the identification, evaluation and management of systemic hypertension in dogs and cats. J. Vet. Intern. Med. 21(3):542-558.

Caselli L., Galanti G., Padeletti L., Nieri M., Cecchi F., Cipollini F., Baldi M., Perrotta L., Vignini S. \& Michelucci A. 2009. Diagnostic accuracy of extended-length electrocardiogram in differentiating between athlete's heart and hypertrophic cardiomyopathy. J. Electroc. 42:636-641.

Chetboul V., Sampedrano C.C., Gouni V., Nicolle A.P. \& Pouchelon J.L. 2006. Two-dimensional color tissue Doppler imaging detects myocardial dysfunction before occurrence of hypertrophy in a young Maine Coon cat. Vet. Radiol. Ultrasound 47(3):295-300.

Ferasin L. 2009. Feline myocardial disease- diagnosis, prognosis and clinical management. J. Feline Med. Surg. 11:183-194.

Fox P.R. 1999. Feline cardiomyopathies, p.621-641. In: Fox P.R., Sisson D. \& Moise N.S. (Eds), Textbook of Canine and Feline Cardiology: principles and clinical practice. W.B. Saunders, Philadelphia.

Granström S., Godiksen M.T., Christiansen M., Pipper C.B., Willesen J.L. \& Koch J. 2011. Prevalence of hypertrophic cardiomyopathy in a cohort of British Shorthair cats in Denmark. J. Vet. Inter. Med. 25(4):866-871.

Gundler S., Tidholm A. \& Häggström J. 2008. Prevalence of myocardial hypertrophy in a population of asymptomatic Swedish Maine coon cats. Acta Vet. Scand. 50(22):1-6.

Harvey A.M., Faena M., Darke P.G. \& Ferasin L. 2005. Effect of body position on feline electrocardiographic recordings. J. Vet. Intern. Med. 19(4):533-
536.

Hsu P.C., Tsai W.C., Lin T.H., Su H.M., Voon W.C., Lai W.T. \& Sheu S.H. 2012. Association of arterial stiffness and electrocardiography-determined left ventricular hypertrophy with left ventricular diastolic dysfunction. PLos One 7(11):e49100.

Killian L., Simpson J.M., Savis A., Rawlins D. \& Sinha M.D. 2010. Electrocardiography is a poor screening test to detect left ventricular hypertrophy in children. Arch. Dis. Child. 95:832-836.

Kittleson M.D., Meurs K.M., Munro M.J., Kittleson J.A., Liu S.K., Pion P.D. \& Towbin J.A. 1999. Familial hypertrophic cardiomyopathy in Maine Coon cats: an animal model of human disease. Circulation 99:3172-3180.

Konno T., Shimizu M., Ino H., Fujino N., Hayashi K., Uchiyama K., Kaneda T., Inoue M., Fujita T., Masuta E., Funada A. \& Mabuchi H. 2005. Differences in diagnostic value of four electrocardiographic voltage criteria for hypertrophic cardiomyopathy in a genotyped population. Am. J. Cardiol. 96:1308-1312.

Lakdawala N.K., Thune J.J., Maron B.J., Cirino A.L., Havndrup O., Bundgaard H., Christiansen M., Carlsen C.M., Dorval J., Kwong R.Y., Colan S.D., Kober L.V. \& Ho C.Y. 2011. Electrocardiographic features of sarcomere mutation carriers with or without clinically overt hypertrophic cardiomyopathy. Am. J. Cardiol. 108:1606-1613.

Mattos B.P., Torres M.A.R., Freitas V.C., Scolari F.L. \& Loreto M.S. 2013. Arritmias ventriculares e hipertrofia ventricular esquerda na cardiomiopatia hipertrófica. Arq. Bras. Cardiol. 100(5):452-459.

McDonald K. 2005. Myocardial disease: feline, p.1328-1341. In: Ettinger S.T. \& Feldman E.C. (Eds), Textbook of Veterinary Internal Medicine. Elsevier Saunders, St Louis.

McDonald K.A., Kittleson M.D., Kass P.H. \& Meurs K.M. 2007. Tissue Doppler imaging in Maine Coon cats with a mutation of myosin binding protein C with or without hypertrophy. J. Vet. Intern. Med. 21:232-237.

Moise N.S., Dietze A.E., Mezza L.E., Strickland D., Erb H.N. \& Edwards N.J. 1986. Echocardiography, electrocardiography, and radiography of cats with dilation cardiomyopathy, hypertrophic cardiomyopathy, and hyperthyroidism. Am. J. Vet. Res. 47(7):1476-1486.

Murphy M.L., Thenabadu N., Soysa N., Meade J., Doherty J.E. \& Baker B.J. 1985. Sensitivity of electrocardiographic criteria for left ventricular hypertrophy according to type of cardiac disease. Am. J. Cardiol. 55:545549.

Nagueh S.F., Appleton C.C.P., Gillebert T.C., Marino P.N., Oh J.K., Smiseth O.A., Waggoner A.D., Flanchkampf F.A., Pellikka P.A. \& Evangelista A. 2009. Recommendations for the evaluation of left ventricular diastolic function by echocardiography. J. Am. Soc. Echocardiography 22(2):107133.

Namdar M., Steffel J., Jetzer S., Schimed C., Hürlimann D., Camici G.G., Bayrak F., Ricciardi D., Rao J., Asmundis C., Chierchia G.B., Sakozy A., Lüscher T.F., Jenni R., Duru F. \& Brugada P. 2012. Value of electrocardiogram in the differentiation of hypertensive heart disease, hypertrophic cardiomyopathy, aortic stenosis, amyloidosis, and Fabry disease. Am. J. Cardiol. 109:587-593.

Neter J., Kutner M.H., Nachtsheim C.J. \& Wasserman W. 1996. Applied Linear Statistical Models. 4th ed. Times Mirror Higher Education Group, USA. 1408p.

Paige C.F., Abbott J.A., Elvinfer F. \& Pyle R.L. 2009. Prevalence of cardiomyopathy in apparently healthy cats. J. Am. Vet. Med. Assoc. 234(11): 1398-1403.

Pelto H., Owens D. \& Drezner J. 2013. Electrocardiographic findings suggestive of cardiomyopathy: what to look for and what to do next. Curr. Sports Med. Rep. 12(2):77-85.

Rowin E.J., Maron B.J., Appelbaum E., Link M.S., Gibson M., Lesser J.R., Haas T.S., Udelson J.E., Manning W.J. \& Maron M.S. 2012. Significance of false negative electrocardiograms in preparticipation screening of athletes for hypertrophic cardiomyopathy. Am. J. Cardiol. 110:1027-1032.

Ryan M.P., Cleland J.G.F., French J.A., Joshi J., Choudhury L., Chojnowska L., Michalak E., Al-Mahdawi S., Nihoyannopoulos P. \& Oakley C.M. 1995. The standard electrocardiogram as a screening test for hypertrophic cardiomyopathy. Am. J. Cardiol. 76:689-694. 
Sampedrano C.C., Chetboul V., Mary J., Tissier R., Abitbol M., Serres F., Gouni V., Thomas A. \& Pouchelon J.L. 2009. Prospective echocardiography and tissue Doppler imaging screening of a population of Maine Coon cats tested for the A31P mutation in the myosin-binding protein $\mathrm{C}$ gene: a specific analysis of the heterozygous status. J. Vet. Intern. Med. 23: 91-99.

Schober K.E., Maerz I., Ludewig E. \& Stern J.A. 2007. Diagnostic accuracy of electrocardiography and thoracic radiography in the assessment of left atrial size in cats: comparison with transthoracic 2-dimensional echocardiography. J. Vet. Intern. Med. 21(4):709-718.

Siegel S. \& Castellan N.J. 1988. Nonparametric Statistics. 2nd ed. McGrawHill, New York. 399p.

Song B.G., Yang H.S., Hwang H.K., Kang G.H., Park Y.H., Chun W.J. \& Oh J.H. 2013. Correlation of electrocardiographic changes and myocardial fibrosis in patients with hypertrophic cardiomyopathy detected by cardiac magnetic resonance imaging. Clin. Cardiol. 36(1):31-35.

Thomas W.P., Gaber C.E., Jacobs G.J., Kaplan P.M., Lombard C.W., Moise N.S. \& Moses B.L. 1993. Recommendations for standards in transthoracic two-dimensional echocardiography in the dog and cat. J. Vet. Intern. Med. 7(4):247-252.

Tilley L.P. 1992. Essentials of Canine and Feline Electrocardiography. 3rd ed. Lea and Febiger, Philadelphia. 470p.

Trehiou-Sechi E., Tissier R., Gouni V., Misbach C., Petit A.M., Balouka D., Sampedrano C.C., Castaignet M., Pouchelon J.L. \& Chetboul V. 2012. Comparative echocardiographic and clinical features of hypertrophic cardiomyopathy in 5 breeds of cats: a retrospective analysis of 344 cases (2001-2011). J. Vet. Intern. Med. 26(3):532-541.

Ware W. 2007. Myocardial disease of the cat, p.300-319. In: Ware W. (Ed.), Cardiovascular Disease in Small Animal Medicine. Manson Publishing, London.

Wess G., Schinner C., Weber K., Küchenhoff H. \& Hartmann K. 2010. Association of A31P and A74T polymorphisms in the myosin binding protein C3 gene and hypertrophic cardiomyopathy in Maine coon and other breed cats. J. Vet. Intern. Med. 24:527-532. 